\title{
Project Management Metamodel Construction Regarding IT Departments
}

\author{
HAMZANE Ibrahim $^{1}$, Belangour Abdessamad ${ }^{2}$ \\ Ben M'sik Faculty of Science \\ Hassan 2 University Casablanca \\ Morocco
}

\begin{abstract}
Given the fast technological progress, the need for project management continues to grow in terms of methodology and new concepts. In this article, we will build a framework of generating a metamodel that we will apply on the project management to generate a generic metamodel of project management, in this approach we will be based on two methodologies of project management; predictive method (ex: PRINCE 2), Agile method (ex: SCRUM). The goal of this research is to validate and apply this methodology on all the components of IT Governance then to aggregate the metamodels to restore a global metamodel for all IT Governance domains.
\end{abstract}

Keywords—MDA; MDE; SCRUM; PRINCE 2; PMBOK; IT

\section{INTRODUCTION}

There is no truth; there are only viewpoints. In other words; we, our ability to see, to interpret is a result of a conception that we have produced during our life. Therefore, we can only perceive models designed and give points of view based on our repository. Thus, the human is adapted to model and reproduce the elements that surround him to better study and use them; as a result, we created programs and machines that help us in our various works.

The emergence of computers today has contributed to its trivialization, which gradually ranks it among other industries. Researchers and manufacturers have agreed that the rise of models and the separation between business and technology will be a very good asset to develop this area, also the fact of use modeling as a massive production tool rather than just a documentation task. This approach led to the birth of the notion of Model-Driven Engineering (MDE [7]).

As an example, IT project management is such a vast and evolving field [4], which allows structuring the different phases of projects, for an optimal organization to meet the objectives of the projects. So, is there a way to aggregate the set of methodologies in a single model that will serve as a basis for our studies in project management? In the following, we will create a project management metamodel using an MDE approach based on an agile framework and a predictive framework.

This paper is organized in the following sections. Section 2 describes related work, which somehow influence our work. Section 3 presents an overview of the Project Management and the MDE whose main goal is to focus on models in order to improve the process. Section 4 describes the approach of metamodel construction theoretically. In Section 5, we apply the approach to project management domain and present metamodel for the case study. Finally, Section 6 summarizes general considerations on present possibilities and announces future work.

\section{RELATED WORK}

Recently, many research efforts have been devoted to develop a new project management models in different project management fields in order to get better results [18], improving the quality [17], securing projects, and representing project risks [19].

Moreover, the need for standardizing process descriptions in order to support interchange and fusion of process increased. Eric Knauss [20] described the advantages of using Object Management Group's standard Meta Object Facility (MOF) to represent requirement Engineering process. MOF is a standard supported by the Object Management Group (OMG) [21]: it defines a generic pattern for the construction of systems.

In the following we are going to propose an approach to extract a meta-model for project management based on MDE. The proposed approach is applied to two project management frameworks: Agile and Predictive.

\section{PRELIMINARIES}

\section{A. Project Management}

Project management is an area that was born at the end of the 19th century when many companies have discovered the need for effective communication and coordination work between individuals [13]. It is an approach aimed at organizing the smooth running of a project from start to finish.

It has gained great popularity in recent decades. This is due to the wide range of benefits offered by project management in an organizational environment characterized by a rapid and changing environment, increasingly fierce competition and demanding customers.

Companies have huge expectations for their projects, but in reality, things are not happening as planned especially in the IT world.

The project management methodology helps managers through every step of a project. It starts by helping the manager to plan, initiate and implement the project. The methodologies even facilitate the closure of the project. Managers can use these templates to plan their tasks and achieve their goals. 
But different methodologies will benefit different projects, and project management models are not all effective for different tasks. To find out which method is right for you, you will need to familiarize yourself with these methodologies and their differences.

\section{B. $M D E$}

Model-Driven Engineering is a discipline of software engineering, it is a generative approach used to generate systems or specific parties of information systems from their models, using several modeling languages called DomainSpecific Modeling Languages (DSML), these generic models are called Metamodel.

Thus, after the emergence of several forms of Meta-Model, it is necessary to define a common language of metamodeling format also known as Meta-Object Facility (MOF), and to define an approach to the construction of the models; which is the Model-Driven Architecture (MDA [9]).

The MDA defines a structured specification architecture divided into four distinct types of models namely:

- Computational Independent Model (CIM); Independent models of computerization called.

- Platform-Independent Models (PIM).

- Model Specific Platform (PSM); Platform-specific models.

- Platform Description Model (PDM); Platform descriptive models.

Note that a CIM models the requirements of a system and defines a common ontology in the system; the purpose of the PIM is to describe the business knowledge of a domain while the PDM models the system's execution platform. Once we know PIMs we can then transform the PIMs into other PIMs for interoperability needs or to produce PSMs targeting a specific platform based on PDM.

\section{BUILDING A METAMODEL APPROACH}

To build a metamodel, our approach is based on four steps (Fig. 1)

First, we produce a reference framework of a given subject, it contains important elements that should be included in the metamodel. Then a second step is to gather existing models of the subject, note that the more models we gather the best is the quality of our metamodel. Then we analyze the concepts using matching technics. Them, finally we optimize the concepts in one metamodel containing an aggregation to all models.

Thus, find bellow the process to produce a model from a given subject:

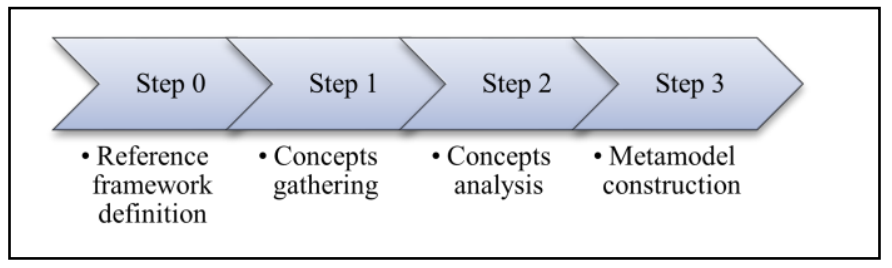

Fig. 1. Metamodel Construction Framework.

\section{A. Step 0: Reference Framework Definition}

The definition of a reference framework (Fig. 2) is an essential step to delimit the field of a search, it is a set of rules and concepts interconnected to carry out research and find out the relationship $\left(\mathrm{R}_{\mathrm{i}}\right)$ between concepts $\left(\mathrm{C}_{\mathrm{i}}\right)$.

In order to establish a metamodel of a target system, the reference framework allows us to delimit our system according to several views by framing system requirements [8] (as example using WH questions like what, who, by whom and how), so it allows us to generate a set of concepts and relationships (1) that must be included in the metamodel. It contains abstractions of the first layer of the metamodel.

$\operatorname{Ref}=\{C j, R j ; \forall j \in N ; C j \in R e f, R j \in R e f\} / C j, R j \in P I M G(1)$

Where Ref is the reference framework, $\mathbf{P I M}_{\mathbf{G}}$ is the metamodel, $\mathbf{C}_{\mathbf{x}}$ is a concept inside the reference framework and $\mathbf{R}_{\mathbf{x}}$ is the relationship between concepts.

\section{B. Step 1: Concepts Gathering}

We have several models of the same system that we want to create the metamodel, it's deferent views of the same system, each model (PIM) has its specificities that everyone considers important during its implementation.

There are several intersections between the different PIMs, thus, to obtain a reliable metamodel it is necessary to include in the meta-model all the intersections between the different PIM that the system can represent.

Later on, we will consider that a reference framework is an ideal metamodel $\left(\mathrm{PIM}_{\text {ideal }}\right)$ and we will call $\mathrm{PIM}_{\mathrm{i}}$ a given modelization of the system.

\section{Step 2: Concepts Analysis}

As technics of concepts analysis, we can rely on the following approach [3]:

- Generative approach (Based on the name of the reassembled concepts).

- Interpretive approach (Functional interpretation of concepts).

- Hybrid approach (a combination of generative and interpretative approach)

- Factorial Analysis of Concepts (AFC); consists in factoring concepts according to the axes defined in the reference framework

- Relational Analysis of Concepts (ARC); consist in factoring the concepts according to the hierarchical level of their relations

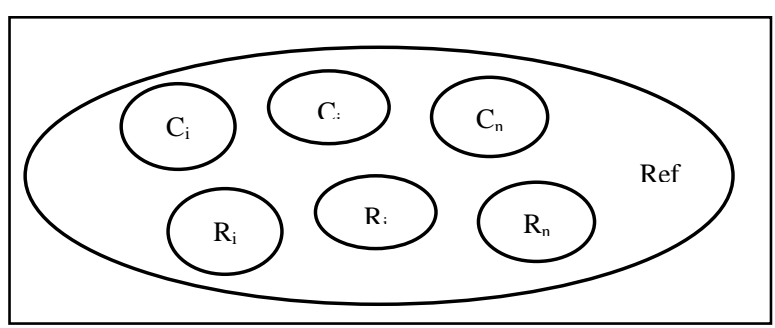

Fig. 2. Reference Framework Modelization. 


\section{Step 3: Metamodel Construction}

The metamodel is an intersection of all models (see red zone in Fig. 3). Where Ideal PIM represents the frame of reference and PIM1, PIM2 and PIM3 are models of the same system.

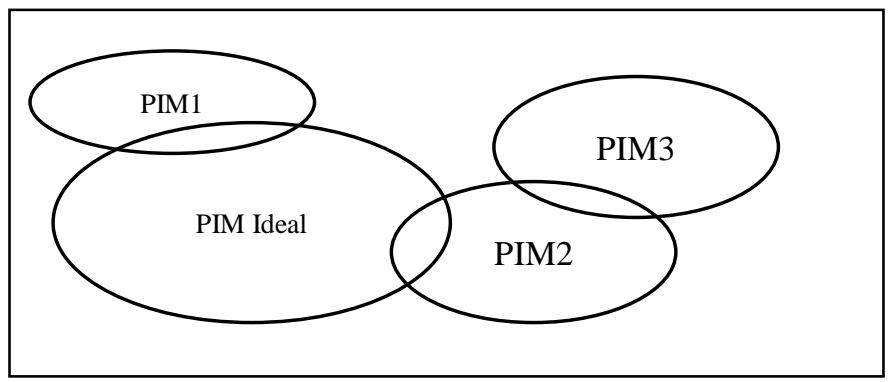

Fig. 3. Reference Framework Modelization.

Therefore, the metamodel will be the union of all analyzed concepts (2).

$\mathrm{PIM}_{\mathrm{G}}=\bigcup_{i}^{j} P I M i \cap P I M j \quad / i \neq j$

\section{CASe Study: Project Management}

In the following, we will apply the explained approach to the Project Management business unit to produce a unique model for the project management field.

Among the most used project management methods [16], especially in the computer world, we find mainly the cyclic models (or agile mode such as SCRUM) and the stepped models (or predictive mode such as PRINCE 2, Y cycle or $\mathrm{V}$ cycle).

\section{A. Project Management in Agile Mode}

The way a project is managed is essentially characterized by two aspects: the division of the project into several stages also called "sprints" or iterations and the management of the team. Agile project management focuses on value. It allows project managers to provide methodically prioritized work of unparalleled quality.

At the end of each sprint, the team that intervened reviews the work done. The lessons learned from critiquing an iteration are used to determine what should be the next stage of the project.

As the name suggests, this project methodology is flexible [15]. This setting explains why it appeals to customers looking for flexibility. When customers are expected to finalize their needs before prototypes can be tested, the associated costs and long lead times often cripple the project. Agile project management is about adapting to change, even at an advanced stage of development. The first is to offer the features with the greatest commercial value and necessary to launch the product. In the context of a managed project in agile mode, the quality of the communication and the managerial abilities of the project manager are essential.

\section{B. Manage a Project with Predictive Methods}

There are several types of predictive project methodologies. The best known are the $\mathrm{V}$ cycle or cascade cycle [6].
Originally born in the industrial sector, the V cycle consists of cutting into 9 phases that are divided between the strategic pole and the technical pole and are always the same:

- Requirements analysis

- Specifications

- Architectural design

- Detailed design

- Production

- Unit tests

- Integration tests

- Validation tests

- Functional tests

The entire project is treated in one block and the project managers who use this method know it at the fingertips because it is always the same. But this implies that there is little room for maneuver if the customer needs change along the way. Similarly, predictive project management requires validation steps essential to the continuation of the project.

Particularly suitable for a client who knows exactly where to go and how to get there, the predictive project mode is much less so for a large and innovative project that will need to evolve over the water and new recommendations made by the team. Because it is by experience much more efficient and offers the customer a very significant latitude agile project management is more common in the IT world than the predictive methods.

\section{Reference Framework Definition}

As there are many facets to see a problem [14], there are several types of reference framework. It's aimed to clarify the subject of research, present a complete vision and give a structured form to the answers of any subject.

In the following, we will use the "four worlds framework" introduced by Rolland in 1998 [5].

The original system framework (Fig. 4) contains four axes:

- The subject world contains the knowledge of the domain about which the proposed IS has to provide information. It contains real-world objects, which become the subject matter for system modeling.

- The system world includes specifications at different levels of detail of what the system does. It holds the modeled entities, events, processes, etc. of the subject world as well as the mapping onto design specifications and implementations.

- The usage world describes the organizational environment of the information system, i.e. the activity of agents and how the system achieves the work, including the stakeholders who are system owners and users. The usage world deals with the intentional aspects of the IS to be built whereas the subject world refers to the domain it shall represent. 
- The development world focuses on the entities and activities, which arise as part of the engineering process itself. It contains the processes which create the information system i.e. processes that involve analysis and understanding of the knowledge contained in the other worlds and representation of that knowledge.

By applying the same framework to project management applied to an IT department, we obtain the following (see Fig. 5):

- The subject world contains the response to What is the project management (set of processes, roles, and indicators to lead the project).

- The system world includes specifications of By What we manage projects (using metrics and models).

- The usage world describes the organizational environment, it gives a response to Why we use project management (to create value, manage time and improve the quality).

- The development world contains the activities, it's more like How the project management will get results (using activities, and phases in order to produce work products).

This reference framework is a very important tool that gives us a clear understanding of our subject; also it's the first step to model the system.

\section{Concepts Gathering}

As we explained previously, we have several Project Management Methodologies (stepped models and cyclic patterns), considering IT domain we have PRINCE 2, PMP, V cycle... as stepped models and SCRUM, XP, TDD ... as cyclic patterns. In the following, we will choose PRINCE 2 and SCRUM in our study.

1) PRINCE 2: Projects In Controlled Environment is a process-oriented method developed by the British government and accredited by Axelos, based on best practices in project management [10]. This flexible methodology applies to all companies and only for a defined scope project. "Built upon seven principles, themes and processes, PRINCE2 can be tailored to meet specific requirements" [2]. In this methodology (see Fig. 6) each process is determined based on input elements, outputs, objectives, and activities.

2) SCRUM: An agile project management methodology, it is used particularly in software development. It's "a framework within which people can address complex adaptive problems, while productively and creatively delivering products of the highest possible value." [1].

The SCRUM method implies that the project progresses through the setting up of series of "sprints" [11]. Each time a sprint is launched, a planning meeting is organized so that each team member can commit to the number of tasks they will be able to perform, as well as the creation of the "sprint backlog", which is the overall list of tasks to be done during the sprint.
Each day of the sprint, all team members (as well as the product manager and the SCRUM Master) must attend the daily SCRUM meeting. It should not last more than 15 minutes [12], and allows team members to share with others what they did the day before, what they are working on the same day, and identifying any issues that could hinder the smooth running of the sprint. This meeting allows you to synchronize all members of the team.

The end of a sprint is marked by a debriefing session to present the completed work to the product manager, and share information that can influence the next sprint.

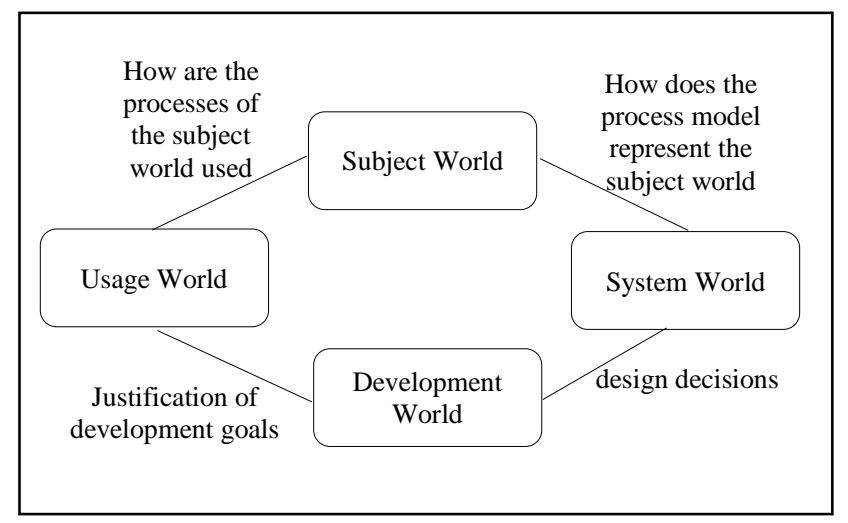

Fig. 4. The Four Worlds of Process Engineering.

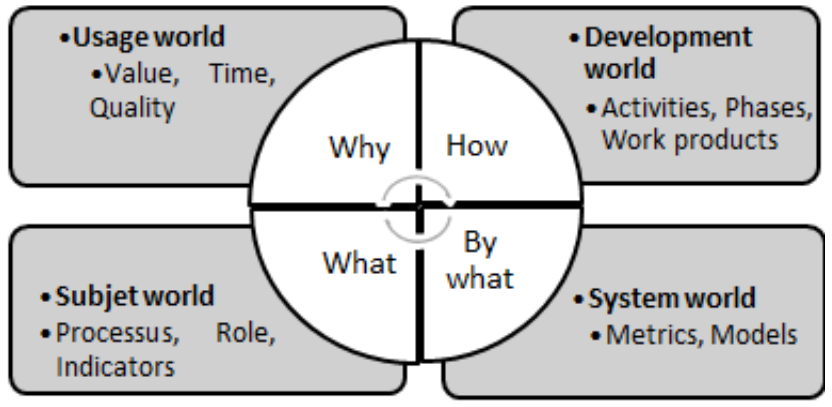

Fig. 5. Reference Framework Modelization.

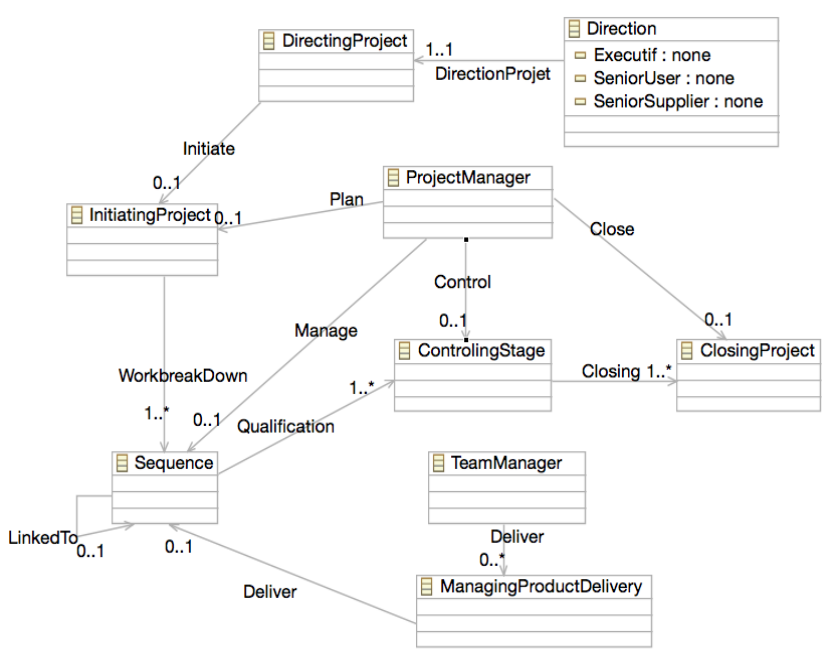

Fig. 6. PRINCE 2 Metamodel. 
The method, therefore, proposes a very iterative approach to project management. The success of this method relies on the strict respect of each person's roles, as well as on short, rigorous and flexible work cycles. The respect of these rules grants at the same time a great autonomy and freedom to the whole team. Given the growing complexity of innovative projects, the SCRUM method seems to be the best solution to meet the execution requirements of the latter, which explains the success it meets today.

See in Fig. 7 below the model of SCRUM method:

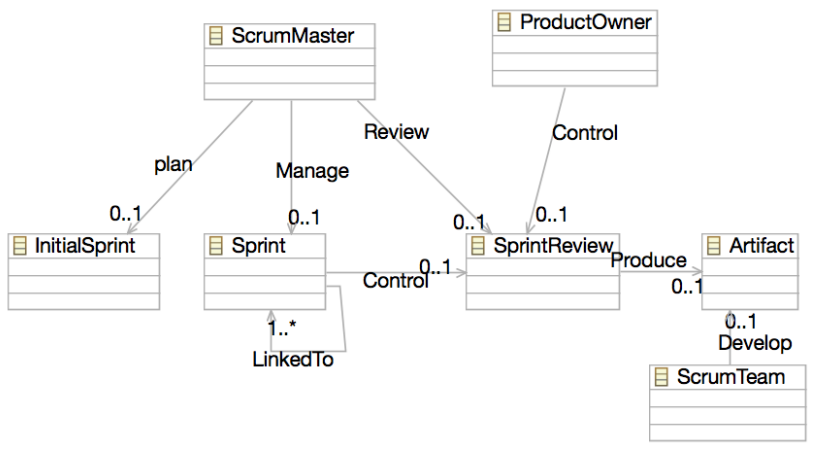

Fig. 7. SCRUM Metamodel

\section{E. Concepts Analysis}

A functional concept comparison will give us Table I.

TABLE. I. FUNCTIONAL COMPARISON BETWEEN PROJECT MANAGEMENT FRAMEWORKS

\begin{tabular}{|l|l|}
\hline SCRUM MODEL & PRINCE 2 MODEL \\
\hline Scrum Master & Project Manager \\
\hline Sprint & Sequence \\
\hline Development team & Team Manager \\
\hline Initial Sprint & Initiating Project \\
\hline Sprint Review & Controlling Stage \\
\hline Artifact & Managing Product Delivery \\
\hline Project Owner & Direction \\
\hline
\end{tabular}

\section{F. Metamodel Construction}

While making the intersection of the models, we got our final metamodel (Fig. 8).

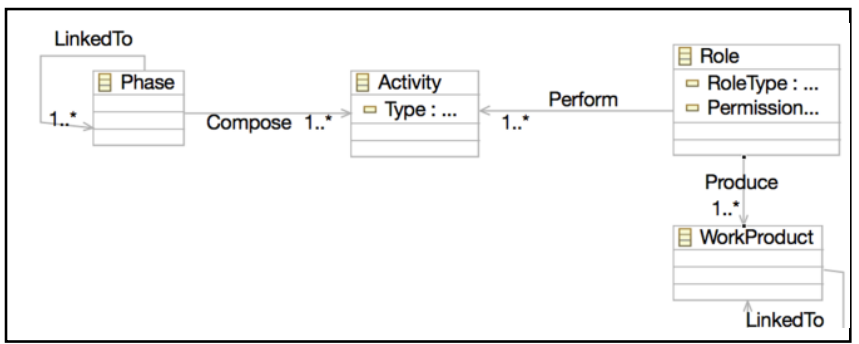

Fig. 8. Proposed Metamodel.

\section{CONCLUSION AND FUTURE WORK}

We reviewed some basic concepts of MDA then we proposed an approach to extract a meta-model. Subsequently, we applied this approach to two project management frameworks (Agile and Predictive), using mechanisms to make the meta-models reliable. This work finally allowed us to establish a meta-model for project management that will later serve as the first step of our global meta-model of IT governance.

Our goal is to define a project management model that will be made up of other models by representing them more globally way.

Subsequently, our general model can constitute a foundation of communication between the different frameworks, so it can be at the origin of the enrichment of other frameworks.

\section{REFERENCES}

[1] Ken Schwaber, Jeff Sutherland, "The Definitive Guide to Scrum: The Roles of the Game", 2017 Edition, available at www.scrum.org.

[2] AXELOS, "Managing Successful Projects with PRINCE2", 2017 Edition.

[3] Z. Ibn Batouta, Multi-criteria analysis and advanced comparative study between automatic generation approaches in software engineering, 2015. Vol.81. No.3.

[4] HAMZANE, I., \& BELANGOUR, A. (2019). Implementation of a decision system for a suitable IT governance framework. International Journal of Computer Science and Information Security (IJCSIS), 17(5).

[5] Rolland, C. (2012). A Comprehensive View of Process Engineering, 124.

[6] Bouchard, B., \& Imbeau, G. (2019). Gestion de projets informatiques.

[7] S. Kent, "Model driven engineering," in Proceedings of the Third International Conference on Integrated Formal Methods, pp. 286-298, Turku, Finland, May 2002.

[8] Gmati, I., Nurcan, S., Gmati, I., \& Nurcan, S. (2012). Un cadre de reference pour analyser les exigences d'alignement métier / système d'information.

[9] A. Kleppe, J. Warmer, and W. Bast, MDA Explained: The Model Driven Architecture: Practice and Promise, AddisonWesley Professional, Boston, MA, USA, 2003, ISBN:032119442X.

[10] Christian Descheemaekere. AXELOS, La méthode Prince2, DUNOD.

[11] Chaplin David, SCRUM Méthode Agile, Editions ENI, OPEN IT.

[12] Ken Schwaber and Jeff Sutherland, The Scrum Guide, scrum.org.

[13] Jean-Claude Corbel, Management de projet : Fondamentaux - Méthodes - Outils, Eyrolles; Édition : 3 (28 juin 2012).

[14] Bégin, C. (2008). Les stratégies d'apprentissage: un cadre de référence simplifié. Revue des sciences de l'éducation, 34(1), 47-67.

[15] Rota, V. M. (2011). Gestion de projet agile: avec Scrum, Lean, eXtreme Programming... Editions Eyrolles.

[16] Peterson R., 2004, Information strategies and tactics for information technology governance, in Strategies for Information Technology Governance, book edited by Van Grembergen W., Idea Group Publishing.

[17] Eva-Maria Schön, Jorge Sedeño, A Metamodel for Agile Requirements Engineering, Journal of Computer and Communications, 2019, 7, 1-22, scientific research publiching.

[18] Souad AHRIZ, Abir EL YAMAMI, Cobit 5-Based Approach for IT Project Portfolio Management: Application to a Moroccan University, IJACSA, Vol. 9, No. 4, 2018.

[19] Abir EL YAMAMI, Souad AHRIZ, Representing IT Projects Risk Management Best Practices as a Metamodel, Engineering, Technology \& Applied Science Research, Vol. 7, No. 5, 2017.

[20] Ferrari, R. (2019). Towards a Meta-model for Requirements-Driven Information for Internal Stakeholders. In Requirements Engineering: Foundation for Software Quality: 25th International Working Conference, REFSQ 2019, Essen, Germany, March 18-21, 2019, Proceedings (Vol. 11412, p. 262). Springer.

[21] OMG Meta Object Facility (MOF) Home Page (2006) www.omg.org/mof/ 